\title{
Periosteal Chondrosarcoma
}

National Cancer Institute

\section{Source}

National Cancer Institute. Periosteal Chondrosarcoma. NCI Thesaurus. Code C7357.

A chondrosarcoma arising from the surface of bone. It is characterized by a lobulated growth pattern, high mitotic activity, myxoid stroma formation, and necrotic changes. It occurs in adults. Clinical presentation includes pain, and sometimes swelling. 